\title{
A CONSPICUOUS POPULATION OF THE LONG-SNOUTED SEAHORSE, HIPPOCAMPUS GUTTULATUS (ACTINOPTERYGII: SYNGNATHIFORMES: SYNGNATHIDAE), IN A HIGHLY POLLUTED MEDITERRANEAN COASTAL LAGOON
}

\author{
Francesco TIRALONGO ${ }^{1,2^{*}}$ and Rossella BALDACCONI ${ }^{1}$ \\ ${ }^{1}$ Ente Fauna Marina Mediterranea, Avola, Siracusa, Italy \\ ${ }^{2}$ Laboratory of Experimental Oceanology and Marine Ecology, DEB - University of Tuscia, \\ 00053 Civitavecchia, Roma, Italy
}

Tiralongo F., Baldacconi R. 2014. A conspicuous population of the long-snouted seahorse, Hippocampus guttulatus (Actinopterygii: Syngnathiformes: Syngnathidae), in a highly polluted Mediterranean coastal lagoon. Acta Ichthyol. Piscat. 44 (2): 99-104.

Background. Seahorses are considered vulnerable and endangered fish species in many parts of the world. We found a conspicuous and stable population of Hippocampus guttulatus Cuvier, 1829 in the Mar Piccolo of Taranto (Ionian Sea), known of its substantial pollution and fluctuations in environmental parameters. The aims of our study were to demonstrate the role of habitat protection in the conservation of this species, the adaptability of the long-snouted seahorse to the water pollution and variable physico-chemical parameters, as well as the habitat preferences of $H$. guttulatus under particular conditions of this coastal lagoon.

Materials and methods. The areas of diving were randomly selected within both parts of the Mar Piccolo of Taranto. Observations were based on snorkelling and scuba diving at different depths from 0 through $4 \mathrm{~m}$. For each dive, in each inlet, all types of environment were explored, divided in four categories based on the nature of the substrate. From the summer of 2011 to the summer of 2013, a total of 23 days of observations were carried, for a total period of $69 \mathrm{~h}$.

Results. A total number of 196 sightings of Hippocampus guttulatus were recorded. The data show a clear preference of the fish studied for the artificial hard substrates, piers and wharves in particular. Only 3 specimens were observed on algal meadows. The western part of the lagoon harbours the largest number of the specimens. Concerning both depth and the three years period, no significant differences were found in the abundance.

Conclusion. This study highlights the ecological importance of the coastal lagoon of the Mar Piccolo of Taranto. We report quantitative data about this population of seahorses with considerations and discussions about the presence and distribution of the specimens, their preferred substrates, and the peculiar polluted environment that they inhabit. Future studies are necessary to better understand the role of habitat protection for seahorses and to improve protection measures for the management and conservation of the species.

Keywords: Habitat preference, seahorses, Ionian Sea, marine pollution, coastal lagoons

\section{INTRODUCTION}

Seahorses are unusually shaped fishes. They lack the pelvic and caudal fins and their "sea horse" name comes from the unusual equine shape of their head. In the Mediterranean Sea, there are three species of the genus Hippocampus Rafinesque, 1810: Hippocampus guttulatus Cuvier, 1829, Hippocampus hippocampus (Linnaeus, 1758), and Hippocampus fuscus Rüppel, 1838 (see Gokoglu et al. 2004, Filiz and Taşkavak 2012, Filiz et al. 2013). This latter species is a Red Sea immigrant. In Mediterranean Sea and in particular in the Italian seas, H. guttulatus is absent or rare in many coastal areas. However, both
H. guttulatus and H. hippocampus are distributed in all Italian seas (Relini and Lanteri 2010).

All these species inhabit shallow inshore waters. The European seahorses species (Hippocampus guttulatus and H. hippocampus) are typically associated with seagrass and macroalgal bed habitats. In particular, H. guttulatus is usually reported from seagrass beds while $H$. hippocampus inhabits soft bottoms among rocks and algae (Curtis and Vincent 2005). Their diet is based on crustaceans like amphipod-, mysidacean-, and decapod larvae (Kitsos et al. 2008, Gurkan et al. 2011). Seahorses are characterized by a low mobility and a small home range (Curtis and

\footnotetext{
${ }^{*}$ Correspondence: Dr. Francesco Tiralongo, Ente Fauna Marina Mediterranea, Via M. Rapisardi, trav. 8, n², 96012, Avola, Siracusa, Italy, phone: +39 0931833184, e-mail: (FT) fra.tiralongo@hotmail.it, (RB) rossella_baldacconi@msn.com.
} 
Vincent 2006). Furthermore, they have a particular reproductive biology with low fecundity, long incubation period, and high parental care (Wilson et al. 2003). The genus includes about 36 species, distributed throughout the temperate and tropical waters of the world (Nelson 2006).

Seahorses are threatened and endangered in many parts of the world (Scales 2010). Seahorse populations are in decline in many areas that have been studied (Martin-Smith and Vincent 2005, Vincent et al. 2011). Human related activity like fisheries (bycatch), unsustainable collecting for commercial purpose, habitat destructions, and pollution are the principal causes that pose a threat to seahorse species (Vincent et al. 2011). However, also natural changes can have an important role in the depletion of species (Aurélio et al. 2013). Hippocampus guttulatus populations demonstrate a patchy distribution and at the majority of locations they are rare (Foster and Vincent 2004). It is an endangered and vulnerable species listed in Bern Convention (Appendix II), Barcelona Convention (SPA/BIO Protocol - Annex II) and, as all species of seahorses, it is included on Appendix II of the Convention on International Trade in Endangered Species of Wild Fauna and Flora (CITES) (Abdul Malak et al. 2011). Furthermore, H. guttulatus is listed in the IUCN Red List (Woodall 2012) as "data deficient".

Paradoxically, we have recorded the presence of an abundant population of the species Hippocampus guttulatus in a coastal lagoon-Mar Piccolo of Taranto-one of the most polluted and disturbed areas of the Mediterranean Sea. (Results of another study on this population were only recently published by Gristina et al. 2014). We would like to emphasize the importance of this lagoon as an important naturalistic area and a refuge for this vulnerable species. The results of our study demonstrate how this population of seahorses is well adapted to this particular environment and show a clear preference of these fish for artificial hard substratum over the usual algal meadows (reported from elsewhere). We assume that the abundance of the seahorses is mainly due to lack of fishing pressure and to a good availability of food resources. Unfortunately, data about the interaction with pollutants are not available for this area and further studies are necessary.

\section{MATERIALS AND METHODS}

Our study was carried out in the Mar Piccolo of Taranto (north-western Ionian Sea), a coastal lagoon with a surface area of $20.72 \mathrm{~km}^{2}$. The lagoon of the Mar Piccolo is divided into two parts: the western one connected to the sea through two small channels and the eastern part, more distant from the sea and larger. The maximum depths are 12 and $8 \mathrm{~m}$ in the western and eastern part, respectively. Hard substrates are mostly artificial while the natural substrate is represented by sand or silt near the shore and mud in the central zone. The salinity ranges from PSS 34.3 to PSS 37.7 (Alabiso et al. 1997) and it is affected by submarine freshwater springs (citri) and the small rivers. Seawater temperature ranges from $7.1^{\circ} \mathrm{C}$ in winter to $33.6^{\circ} \mathrm{C}$ in summer (Alabiso et al. 1997 ,
Petrocelli et al. 2013). Water mass movement is limited and depends on the wind, the tides, and the mixing of water of different temperature and salinity.

Our underwater visual census activities were based on snorkelling and scuba diving. The study areas were randomly selected. The depth range was between 0 and $4 \mathrm{~m}$. The areas deeper than $1 \mathrm{~m}$ were explored by scuba diving.

Our research included a three-year period, from 2011 through 2013. Observations were more intense in summer, from June through September (in one case until October). Each observation lasted about $3 \mathrm{~h}$ in both lagoon parts. A total of 23 days of observations were carried out, for a total of $69 \mathrm{~h}$. Several specimens observed were photographed. For each dive, in each inlet were explored all types of substrates, divided in four categories, based on the nature of substrate: mussel farms, piers and wharves, artificial reefs, and algal meadows. The observations time was assigned equally to the four environment categories.

The data were analyzed by chi-square test.

\section{RESULTS}

During underwater visual census activities, a total of 196 observations of the long-snouted seahorse Hippocampus guttulatus at a depth range from 0 to $4 \mathrm{~m}$ were recorded. No significant abundance differences were found among depths $\left(\chi^{2}=0.286, \mathrm{df}=3, P=0.963\right)$. Instead, a different situation was present among habitat preferences $\left(\chi^{2}=191.837, \mathrm{df}=3\right.$, $P<0.001)$. A total of 125 observations $(63.78 \%)$ were made on pier and wharf substrates. The remaining sightings included the mussel farms $(57 ; 29.08 \%)$, artificial reefs $(11 ; 5.61 \%)$, and algal meadow with only 3 observations (1.53\%).

No significant differences were determined in the relation to the abundance of the specimens observed in the three years: a total of 64 observations in 2011 (32.65\%), 75 in $2012(38.25 \%)$, and 57 in $2013(29.1 \%)\left(\chi^{2}=2.52\right.$, $\mathrm{df}=2, P=0.284)$. Apart from the first year, when were observed the same numbers of specimens between the mussel farms and piers and wharves, the piers and wharves substrate were inhabited by the largest number of specimens in both 2012 and 2013 (Table 1).

Concerning the differences in abundance between the western and the eastern part of the lagoon, the data clearly show the preference for the western part. Only $41 \mathrm{spec}-$ imens were recorded in the eastern part $(20.92 \%)$ versus the 155 specimens found in the western part $(79.08 \%)$ $\left(\chi^{2}=66.306, \mathrm{df}=1, P<0.001\right)$.

All the specimens observed were healthy and apparently well nourished. During the study period, we observed some males that carrying eggs in their brooding structures: 8 specimens in June 2012 and 9 others in August 2013, in both cases on mussel farms and piers and wharves substrate of the western lagoon part only.

Some of the seahorses observed had a peculiar feature: without skin filaments (Fig. 1). Precisely, we recorded 10 specimens without skin filaments and 14 specimens with only few skin filaments. This feature has caused several misidentifications with the congener-H. hippocampus in the past. 

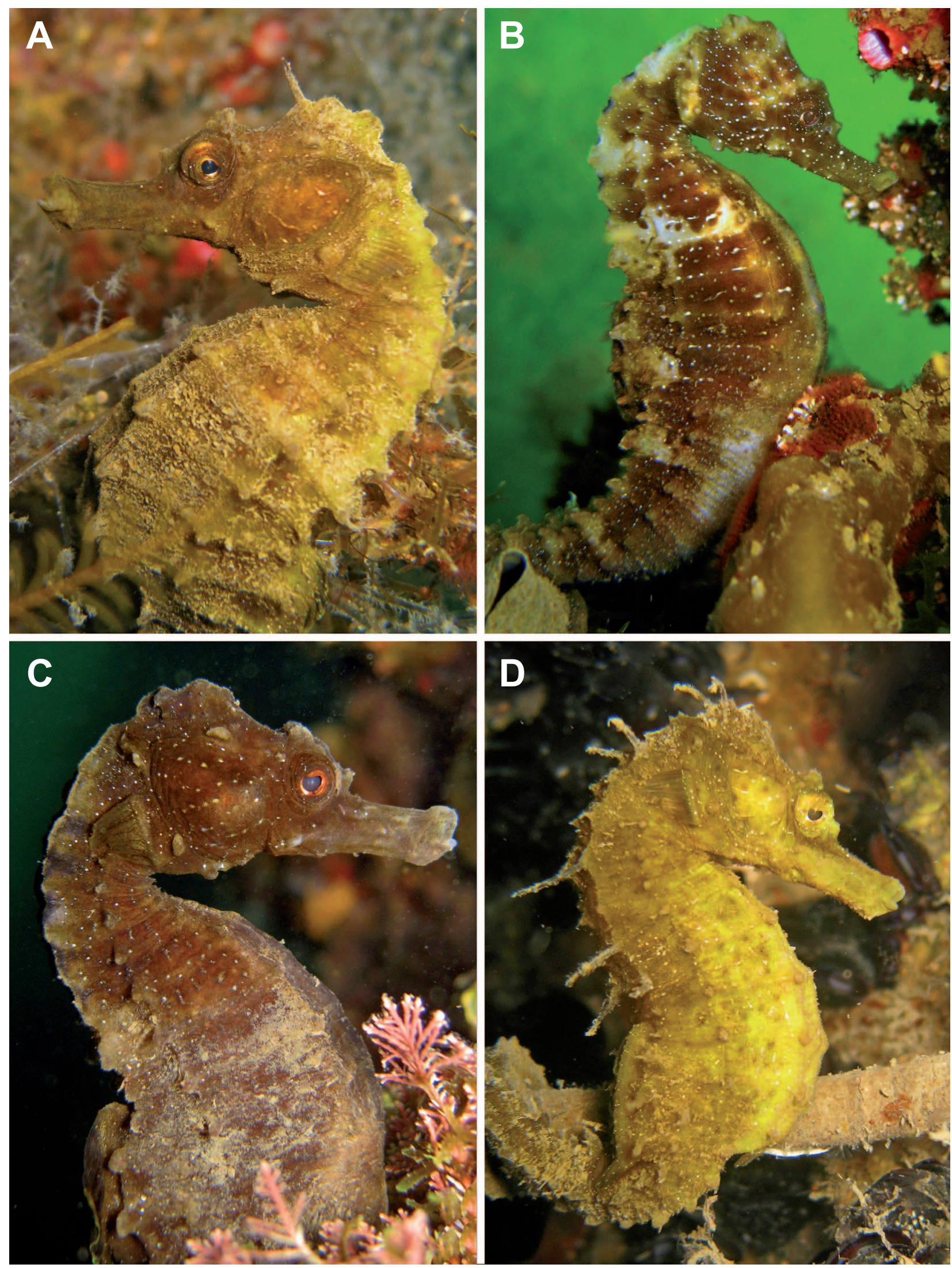

Fig. 1. Selected specimens of Hippocampus guttulatus observed during the diving visual census carried out in the Mar Piccolo of Taranto (Ionian Sea) within 2011-2013; Note that some of these specimens are without skin filaments $(\mathbf{B}, \mathbf{C})$ or with few skin filaments $(\mathbf{A}, \mathbf{D})$ 
However, although with only 5 specimens and only in July 2011, also the other species, Hippocampus hippocampus, was recorded in the western part of the Mar Piccolo of Taranto. In summary, long-snouted seahorses inhabit in both Mar Piccolo parts and, as our chi-square analysis reveals, much prefer the artificial substrate of the western part $\left(\chi^{2}=59.51, \mathrm{df}=1, P<0.001\right)$.

\section{DISCUSSION}

The Mar Piccolo of Taranto is a heavily contaminated body of water (Cardellicchio et al. 2007, Calace et al. 2008). High concentrations of both organic (polychlorinated biphenyls, polycyclic aromatic hydrocarbons, dioxins) and inorganic (heavy metals such as mercury, zinc, copper, lead, and cadmium) pollutants are present (Cardellicchio et al. 2007, Calace et al. 2008). The pollution is caused mostly by industrial and military activities: steel industry, refinery, arsenal, shipyards, military harbour, and industrial port. Despite the contamination, the marine community of the Mar Piccolo is very rich and consisting of native species, some of them rare in other parts of Mediterranean Sea, as well as alien species which reached the basin through naval traffic and aquaculture
(Anonymous and Occhipinti-Ambrogi 2010). In shallow water, a peculiar assemblage established itself on the submerged substrates of the mussel farms, of the piers and the wharves, and of the artificial reefs. It is characterized by a great number of filter feeders: sponges, ascidians, polychaetes, bivalves, barnacles, and bryozoans. The filter feeder communities are composed of numerous gastropods, crabs, starfish, sea urchins, and benthic fishes such as blennies, pipefishes, and seahorses. Coastal lagoons are dynamic systems characterized by intense physico-chemical gradients (e.g., salinity, temperature, and substrate varieties) providing high habitat diversity, thereby forcing the species to adapt to such heterogeneous conditions (Dauvin and Ruellet 2009).

The data collected show the abundance of Hippocampus guttulatus within the Mar Piccolo of Taranto. From our observations it appears that this species prefers to inhabit the artificial hard substrates of mussel farms and piers and wharves, with a greater preference for the latter. Furthermore, although the eastern part of the lagoon occupies a larger surface, the majority of the specimens are distributed in the western part of the lagoon. This is probably due to the fact that the western part of the lagoon is in direct

Number of sightings of Hippocampus guttulatus in the Mar Piccolo of Taranto (Ionian Sea)

Table 1 during the diving visual census carried out within 2011-2013

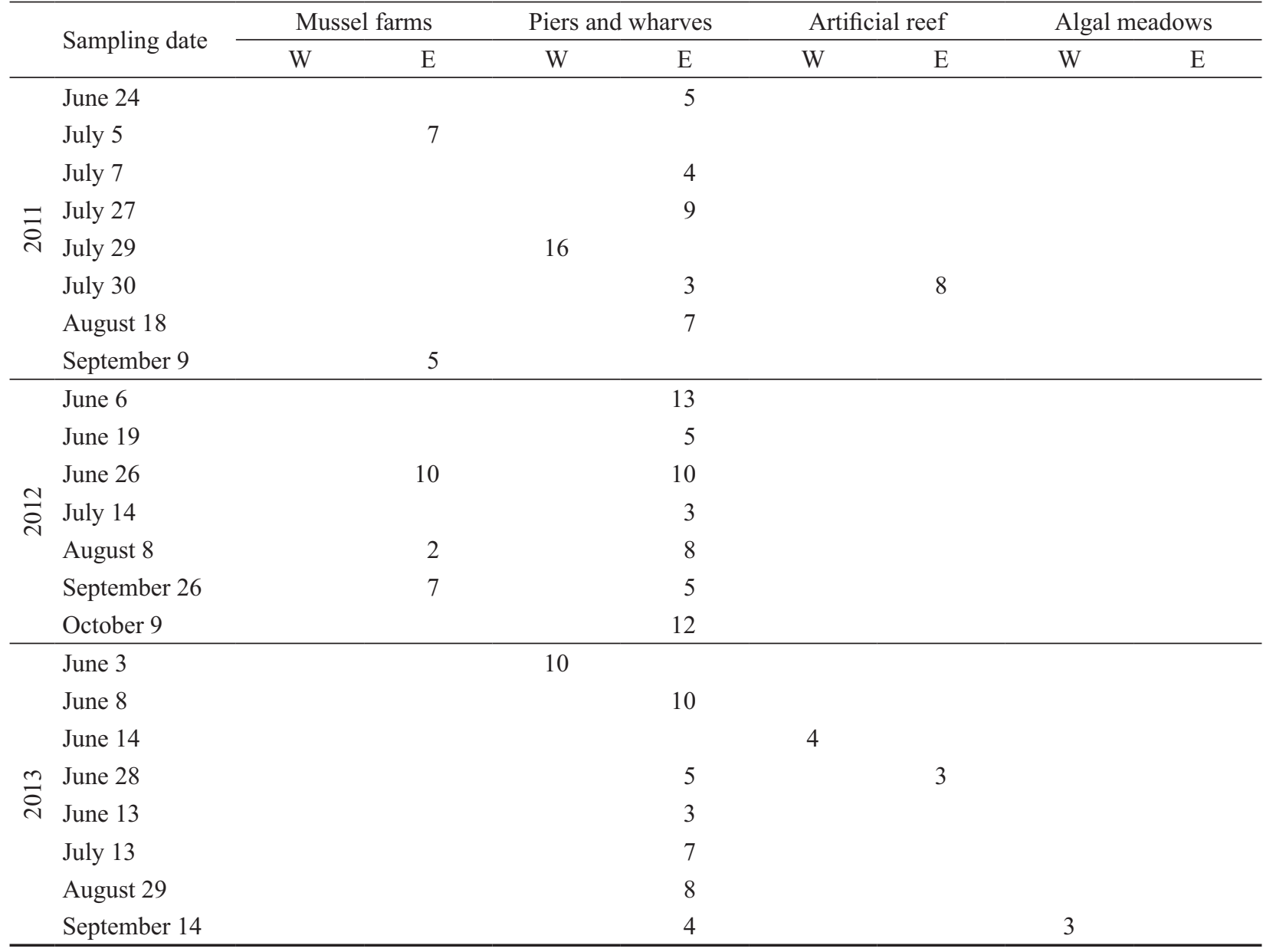

$\mathrm{W}=$ western part of the Mar Piccolo, E = eastern part of the Mar Piccolo. 
communication with the open sea through two canals. This allows an exchange of waters between the lagoon and the sea; therefore the conditions in the western part of the lagoon are more similar to those in the open sea.

Uncommonly for this species, we found only 3 specimens of Hippocampus guttulatus on algal meadows. Other researchers (Foster and Vincent 2004, Curtis and Vincent 2005, 2006, Vincent et al. 2011) reported that $H$. guttulatus inhabited seagrass- or algal beds. The presently reported study is also in partial disagreement with the recent work of Gristina et al. (2014), who also studied the Mar Piccolo of Taranto. The above-mentioned authors described $H$. guttulatus with no habitat preference between algal beds and hard substrates. Consistently with our study, Gristina et al. (2014) also recorded a low abundance of H. hippocampus in the area. Curtis (2006) demonstrated that the presence or absence of skin filaments in European seahorses (H. guttulatus and H. hippocampus) is an unreliable character for the species identification and that the decisive is an analysis of multiple morphological traits (i.e., snout length, head shape, fin rays counts). The above-mentioned study also emphasized the apparent tolerance of Hippocampus species to highly polluted waters. It was impossible, however, to draw conclusions about possible correlation between pollutant concentrations and the abundance of seahorses in different environments are because the relevant parameters were not studied. Seemingly, $H$. guttulatus has found a suitable environment in these waters, also for its reproduction. The established population of $H$. guttulatus in the Mar Piccolo of Taranto suggests that those fish are capable of tolerating a wide range of temperatures of this coastal lagoon, varying between $7.1^{\circ} \mathrm{C}$ in winter to $33.6^{\circ} \mathrm{C}$ in summer (Alabiso et al. 1997, Petrocelli et al. 2013). For comparison, the temperatures in the open sea range from $12.7^{\circ} \mathrm{C}$ in winter to $27.2^{\circ} \mathrm{C}$ in summer. As also hypothesized by Gristina et al. (2014), the presence of this conspicuous population finds its explanation in at least two main causes: the lack of fishing pressure and the high trophic level caused by artificial eutrophication. The water with high content of nutrients is capable of supporting large crustacean populations - potential prey of seahorses - such as amphipod-, mysidacean-, and decapod larvae (Kitsos et al. 2008, Gurkan et al. 2011).

The presence of seahorses contributes to the high biodiversity of the Mar Piccolo despite of the substantial pollution level. It also confirms a good adaptability potential of seahorses to highly altered environments with consistent fluctuations, as has been demonstrated (Aurélio et al. 2013). In others words, this coastal lagoon can be seen as a "marine protected area" where seahorses are protected from the fishing pressure. A similar phenomenon was discussed by Caldwell and Vincent (2012) who recorded unusually high densities of Hippocampus guttulatus and H. hippocampus in the Ria Formosa Lagoon (Portugal) and suggested that their abundance was positively correlated with the effect of no fishing.

Our study emphasizes the importance of the Mar Piccolo of Taranto for the long-snouted seahorse, Hippocampus gut- tulatus, and provides new information about the habitat preference of this vulnerable species that in the area studied inhabits hard substrates, mainly piers and wharves. Further studies are required for better understanding of:

- The effect of protection for seahorse populations;

- The alleged correlation between the presence of this species in the different environments and the respective environmental parameters (including pollutant concentrations);

- Explanations for the preferences for hard substrates instead of seagrass or algal meadows.

\section{REFERENCES}

Abdul Malak D., Livingstone S.R., Pollard D., Polidoro B.A., Cuttelod A., Bariche M., Bilecenoglu M., Carpenter K.E., Collette B.B., Francour P., Goren M., Kara M.H., Massutì E., Papaconstantinou C., Tunesi L. 2011. Overview of the conservation status of the marine fishes of the Mediterranean Sea. International Union for Conservation of Nature and Natural Resources (IUCN), Gland, Switzerland and Malaga, Spain.

Alabiso G., Cannalire M., Ghionda D., Milillo M., Leone G., Caciorgna O. 1997. Particulate matter and chemical-physical conditions of an inner sea: the Mar Piccolo in Taranto. A new statistical approach. Marine Chemistry 58 (3-4): 373-388. DOI: 10.1016/S0304-4203(97)00063-7

Anonymous, Occhipinti-Ambrogi A. (coordinator) 2010. Hotspots of introduction of marine alien species in Italian seas. Rapport de la Commission Internationale pour l'Exploration scientifique de la Mer Méditerranée 39: 427.

Aurélio M., Faleiro F., Lopes V.M., Pires V., Lopes A.R., Pimentel M.S., Repolho T., Baptista M., Narciso L., Rosa R. 2013. Physiological and behavioral responses of temperate seahorses (Hippocampus guttulatus) to environmental warming. Marine Biology 160 (10): 2663-2670. DOI: 10.1007/s00227-013-2259-8

Calace N., Cardellicchio N., Ciardullo S., Petronio B.M., Pietrantonio M., Pietroletti M. 2008. Metal distribution in marine sediments of the Mar Piccolo in Taranto (Ionic Sea, southern Italy). Toxicological and Environmental Chemistry 90 (3): 549-564. DOI: 10.1080/02772240701570420

Caldwell I.R., Vincent A.C.J. 2012. Revisiting two sympatric European seahorse species: apparent decline in absence of exploitation. Aquatic Conservation: Marine and Freshwater Ecosystems 22 (4): 427-435. DOI: 10.1002/aqc.2238

Cardellicchio N., Buccolieri A., Giandomenico S., Lopez L., Pizzulli F., Spada L. 2007. Organic pollutants (PAHs, PCBs) in sediments from the Mar Piccolo in Taranto (Ionian Sea, Southern Italy). Marine Pollution Bulletin 55 (10-12): 451-458. DOI: 10.1016/j.marpolbul.2007.09.007

Curtis J.M.R. 2006. A case of mistaken identity: skin filaments are unreliable for identifying Hippocampus guttulatus and Hippocampus hippocampus. Journal of Fish Biology 69 (6): 1855-1859. DOI: 10.1111/j.1095-8649.2006.01228.x

Curtis J.M.R., Vincent A.C.J. 2005. Distribution of sympatric seahorse species along a gradient of habitat complexity in a seagrass-dominated community. Marine Ecology Progress Series 291: 81-91. DOI: $10.3354 / \operatorname{meps} 291081$ 
Curtis J.M.R., Vincent A.C.J. 2006. Life history of an unusual marine fish: survival, growth and movement patterns of Hippocampus guttulatus Cuvier 1829. Journal of Fish Biology 68 (3): 707-733. DOI: 10.1111/j.0022-1112. 2006.00952.x

Dauvin J.-C., Ruellet T. 2009. The estuarine quality paradox: is it possible to define an ecological quality status for specific modified and naturally stressed marine ecosystems? Marine Pollution Bulletin 59 (1-3): 38-47. DOI: 10.1016/ j.marpolbul.2008.11.008

Filiz H., Filiz M., Taşkavak E. 2013. Artisanal fishery and seahorses (Genus: Hippocampus) in Turkey. Journal of the Black Sea/Mediterranean Environment 19 (3): 354-358.

Filiz H., Taşkavak E. 2012. Field surveys on recent situation of seahorses in Turkey. Biharean Biologist 6 (1): 55-60.

Foster S.J., Vincent A.C.J. 2004. Life history and ecology of seahorses: implications for conservation and management. Journal of Fish Biology 65 (1): 1-61. DOI: 10.1111/j.00221112.2004.00429.x

Gokoglu M., Bodur T., Kaya Y. 2004. First records of Hippocampus fuscus and Syngnathus rostellatus (Osteichthyes: Syngnathidae) from the Anatolian coast (Mediterranean Sea). Journal of the Marine Biological Association of the United Kingdom 84 (5): 1093-1094.

Gristina M., Cardone F., Carlucci R., Castellano L., Passarelli S., Corriero G. 2014. Abundance, distribution and habitat preference of Hippocampus guttulatus and Hippocampus hippocampus in a semi-enclosed central Mediterranean marine area. Marine Ecology (published online 20 Jan 2014). DOI: 10.1111/maec.12116

Gurkan S., Taskavak E., Sever T.M., Akalin S. 2011. Gut contents of two European seahorses Hippocampus hippocampus and Hippocampus guttulatus in the Aegean Sea, coasts of Turkey. Pakistan Journal of Zoology 43 (6): 1197-1201.

Kitsos M.-S., Tzomos Th., Anagnostopoulou L., Koukouras A. 2008. Diet composition of the seahorses, Hippocampus guttula- tus Cuvier, 1829 and Hippocampus hippocampus (L., 1758) (Teleostei, Syngnathidae) in the Aegean Sea. Journal of Fish Biology 72 (6): 1259-1267. DOI: 10.1111/j.1095-8649. 2007.01789.x

Martin-Smith K.M., Vincent A.C.J. 2005. Seahorse declines in the Derwent estuary, Tasmania in the absence of fishing pressure. Biological Conservation 123 (4): 533-545. DOI: 10.1016/j.biocon.2005.01.003

Nelson J.S. 2006. Fishes of the world. 4th edn. John Wiley and Sons, New York, USA.

Petrocelli A., Cecere E., Verlaque M. 2013. Alien marine macrophytes in transitional waters systems: new entries and reappearances in a Mediterranean coastal basin. BioInvasions Records 2 (3): 177-184. DOI: 10.3391/bir. 2013.2.3.01

Relini G., Lanteri L. 2010. Osteichthyes. Biologia Marina Mediterranea 17 (1): 649-674.

Scales H. 2010. Advances in the ecology, biogeography and conservation of seahorses (genus Hippocampus). Progress in Physical Geography 34 (4): 443-458. DOI: 10.1177/ 0309133310364928

Vincent A.C.J., Foster S.J., Koldewey H.J. 2011. Conservation and management of seahorses and other Syngnathidae. Journal of Fish Biology 78 (6): 1681-1724. DOI: $10.1111 / \mathrm{j} .1095-8649.2011 .03003 . \mathrm{x}$

Wilson A.B., Ahnesjö I., Vincent A.C.J., Meyer A. 2003. The dynamics of male brooding, mating patterns, and sex roles in pipefishes and seahorses (Family Syngnathidae). Evolution 57 (6): 1374-1386. DOI: 10.1554/02-090

Woodall L. 2012. Hippocampus guttulatus. In: IUCN 2013. IUCN Red List of Threatened Species. Version 2013.2. www.iucnredlist.org

Received: 29 January 2014 Accepted: 7 April 2014 Published electronically: 30 June 2014 